\title{
Political Intentions and Legal Measures: The Determinants of Policy Decisions
}

\author{
Renate Mayntz \\ $\mathrm{Köln}$
}

\section{Contents}

Introduction

I. Law as a Policy Instrument: What is the Issue?

II. The Analytical Dimensions of Programmes

III. The Determinants of Policy Design - A Causal Model

IV. The Theoretical Potential of Comparative Policy Research

\section{Introduction}

The research reported in this volume and its companion publication ${ }^{1}$ pursues two different objectives which are both covered by the formula "law as instrument of economic policy". The latter volume is concerned with the process of legalisation (or juridification) taking place over time in such areas as wage determination, industrial relations and corporate structure. The perspective of these studies is longitudinal, and the major questions concern changes in the intensity, specificity and objectives of legal regulation. A second set of studies is more concerned with specific policy instruments such as regulation, financial incentives, and public provision, and the way these instruments are used in different countries. Here the perspective is largely comparative, making use of the data collected on the objectives, instruments, and legal measures of energy and of manpower policy in different European countries. These observations are addressed to the second of these two concerns as represented specifically by Terence Daintith's contribution ${ }^{2}$ and therefore take the formula "law as policy instrument" as a starting point. After briefly discussing what this formulation implies and how it relates to the cognitive interests of different disciplines, I will go on to consider what inferences a comparative analysis of legal measures permits with respect to the major determinants of policy decisions. For this purpose I will outline a causal model of policy

1 G. Teubner, ed., Juridification of Social Spheres (1987, Berlin).

2 Terence Daintith, "Law as Policy Instrument: A Comparative Perspective," above, at pp. $3-55$. 
decisions and will ask how an international comparison can help make inferences from explicitly formulated policy decisions to the factors that have shaped them.

\section{Law as a Policy Instrument: What is the Issue?}

To talk about law as policy instrument implies that there are other kinds of instruments which might be used instead. The question is then why law rather than some other policy instrument is being chosen, and what effects this particular choice has:

Figure 1

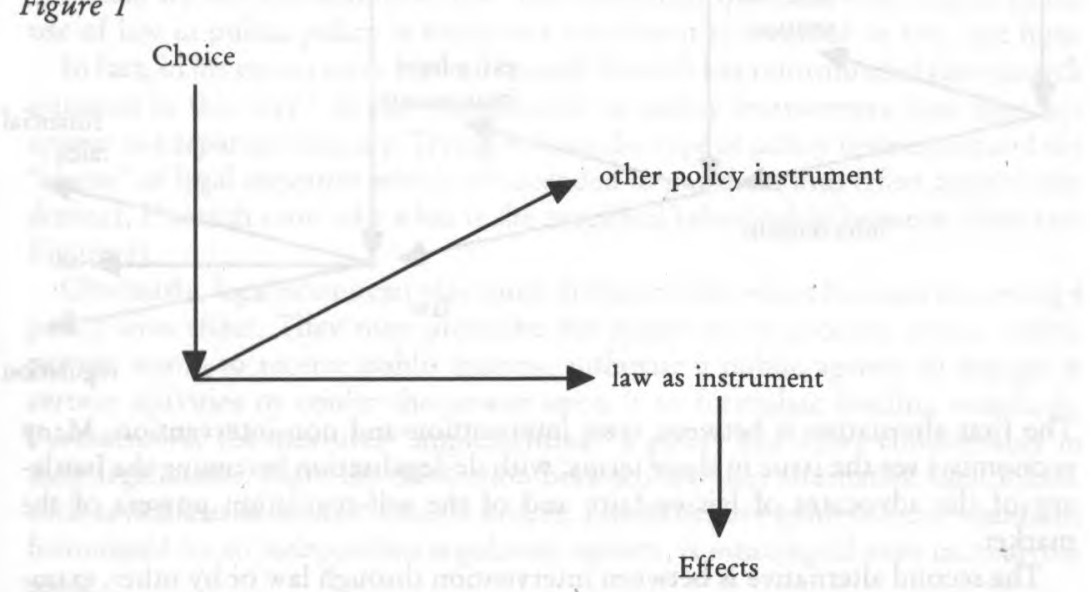

"Legalisation" would here be the consequence of an increasing reliance on law in state intervention, a meaning that must be distinguished from legalisation in the sense of a general increase of legal norms (as distinct from social custom, convention, or informal social norms) in society. ${ }^{3}$ Of course, the growing inclination of the state to formulate legal norms for policy purposes may be an important cause of legalisation in the second sense, but sociologists at least have tended to emphasize other reasons which have to do with the changing integration needs of society. This line of reasoning, which can be traced back to Durkheim, finds clear expression for instance in the work of Kaupen, for whom a multiplication of legal norms reflects the dominance of the problem of social integration, one of Parsons' four functional imperatives. ${ }^{4}$ In the present context, however, "legalisation" is of interest as a reflection of different political intervention styles.

${ }^{3}$ This is the meaning which R. Voigt gives to the term; "Verrechtlichung in Staat und Gesellschaft", in: R. Voigt (ed.) Verrechtlichung, (1980, Königstein) at p. 16.

${ }_{4}$ Wolfgang Kaupen, "Über die Bedeutung des Rechts und der Juristen in der modernen Gesellschaft", in: Kaupen/Werle (eds) Soziologische Probleme juristischer Berufe, (1974, Göttingen) at pp. 23-25. 
Focusing, then, on the choice of law as a policy instrument, it seems important to clarify the nature of the alternatives which this formulation implies. Figure 2 may be helpful in this regard.

\section{Figure 2}

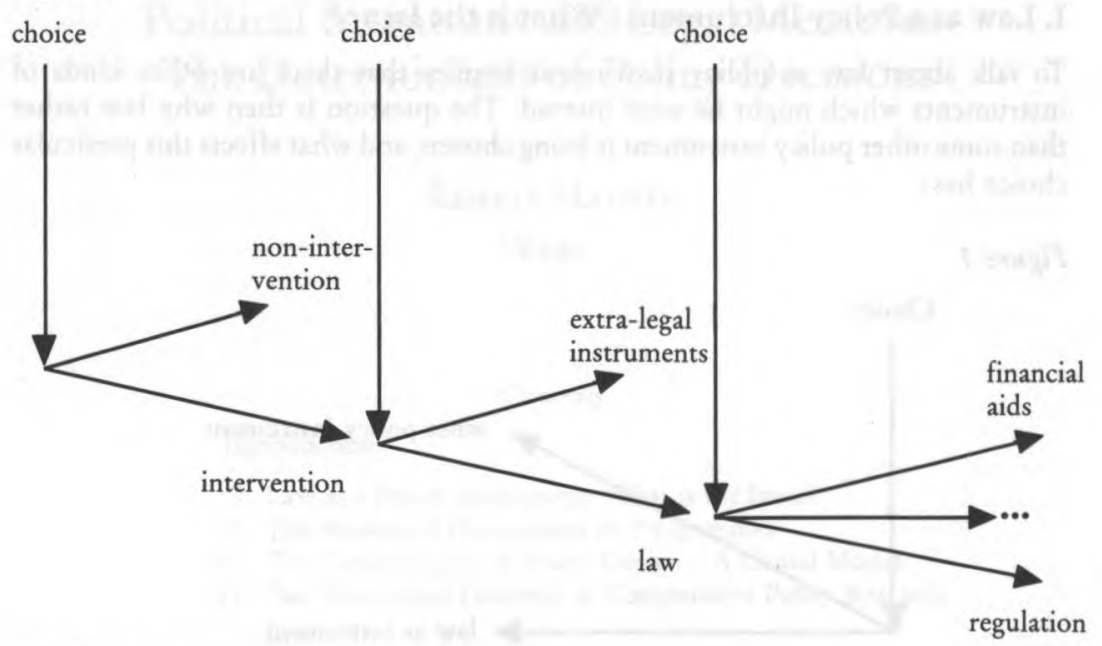

The first alternative is between state intervention and non-intervention. Many economists see the issue in these terms, with de-legalisation becoming the battlecry of the advocates of laissez-faire and of the self-regulation powers of the market.

The second alternative is between intervention through law or by other, extralegal means. Such extra-legal means can be bargaining, informal pressure, or the threat of resorting to legislation - alternative political strategies which the continental European scholar with his ingrained legalism tends to overlook but which are occasionally highlighted by British colleagues. ${ }^{5}$ Another policy instrument which is sometimes considered as an alternative to law is money. ${ }^{6}$ This distinction, as well as the singling out of law as one policy instrument among others, makes a lot of sense in a historical perspective, where rulers have often used money (as well as other gifts, and even their daughters) to further their political intentions and to obtain compliance. In such an historical perspective, legalisation describes the emergence of Max Weber's legal-rational type of political order and of the modern constitutional state. However, when we deal with present societies and speak of policy, the distinction between law and other policy instruments

5 See e.g. T. Daintith, "The Executive Power Today: Bargaining and Economic Control", in J.Jowell and D. Oliver, eds., The Changing Constitution (1985, Oxford) at pp. 174-197.

6 Niklas Luhmann, Politische Theorie im Woblfahrsstaat, (1981, München/Wien) at pp. $94 \mathrm{ff}$. 
undoubtedly loses much of its importance. Today, there is very little really discretionary giving of public money to private actors. The big spending programmes in the fields of social welfare and industrial policy (subsidies) are normally couched in the form of a law; even the procurement of weapons has a legal basis in the budget. Similar arguments could be made with respect to other possible alternatives to "law as policy instrument", such as the public provision of services, and self-regulation, which, if it does not mean simply non-intervention, is usually based on legally conferred rights and procedural norms. It certainly makes a big difference whether modern governments try to reach policy goals by the normative regulation of the behaviour of private parties, by offering incentives for the same purpose or by having public agencies do directly what they wish to be donebut these are not alternatives to law. The interesting question with respect to the use of law in public policy is today not whether it is involved or not, but how.

In fact, in his most recent paper, Daintith himself has reformulated the research question in this way. ${ }^{7}$ In the classification of policy instruments, law does not appear as a separate category. Trying to keep the type of policy instrument and the "shape" of legal measures which are intended to put them into effect analytically distinct, Daintith now asks what is the empirical relationship between them (see Figure 3).

Obviously, legal norms can play quite different roles when it comes to putting a policy into effect. They may prescribe the behaviour of a target group, entitle private actors to receive public money, authorise a public agency to engage in certain activities or confer the power upon it to formulate binding standards. Furthermore, the measures "implementing" a policy can differ considerably in their legal status. Here the distinction between law and alternative legal forms, such as ministerial decrees, cabinet orders, administrative guidelines, or standards formulated by an independent regulatory agency, is meaningful even in a narrow sense.

Figure 3

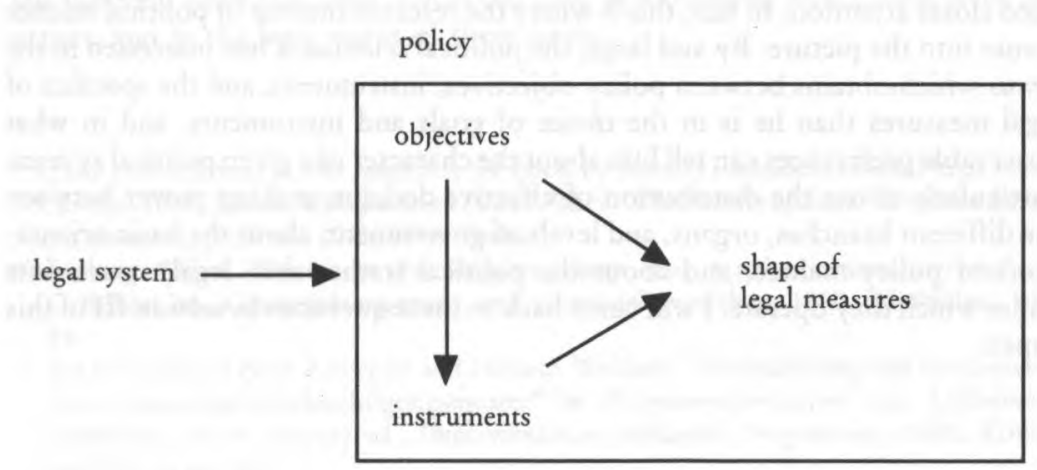

7 T. Daintith, supra note 1. 
The status of legal norms and their specific function in a given policy context are largely determined by the choice of policy instrument, i.e. of how to bring about what the policy-makers want to achieve, with the scope for choice as to the "shape" of legal measures getting narrower as the mode of intervention is formulated in growing detail. Having chosen to try and control the behaviour of private actors instead of resorting to public provision, in the attempt say, to abate pollution, and having further decided to do this not by moral exhortation or through offering financial incentives, but by constraining potential polluters to observe certain emission standards, there may still be the alternative to do this directly by having parliament formulate the corresponding standards or indirectly by setting up an independent regulatory agency to do so, but from this point on very little choice remains as to the status and the function of the legal norms involved. To the extent that this is so, observable relationships between the "instrument" and "legal measure" categories are logical rather than empirical, i.e. the latter appear largely as operationalisation (or specification) of the former. The relationship between objectives and instruments is of a somewhat different nature. Legal restrictions on the central government's scope for authoritative intervention are an important factor of instrument choice, especially where a given choice would interfere with constitutionally guaranteed spheres of autonomy and areas of personal freedom. However, within these constraints there are also other factors at work. Some of the empirical analyses of the incidence of specific instruments (and measures) in different policy areas and with respect to different policy goals suggest implicitly that effectiveness considerations play a major role in making instrument choices. ${ }^{8}$ Thus, a higher incidence of instrument $\mathrm{X}$ in a given context is explained by reference to some characteristic of the target population which renders this particular instrument more effective than other possible alternatives. Apart from the fact that such a (rather rationalistic) interpretation of the behaviour of policy-makers would need ulterior empirical evidence, the many cases where the empirical findings do not lend themselves easily to such an interpretation suggest that there are other factors involved in policy design which need closer attention. In fact, this is where the research interest of political science comes into the picture. By and large, the political scientist is less interested in the nexus which obtains between policy objectives, instruments, and the specifics of legal measures than he is in the choice of goals and instruments, and in what observable preferences can tell him about the character of a given political system, particularly about the distribution of effective decision-making power between the different branches, organs, and levels of government, about the basic orientations of policy-makers, and about the political (rather than legal) constraints under which they operate. I will come back to these questions in section III of this paper.

${ }^{8}$ See especially the contributions by Hans Jarass and Dietrich von Stebut to this volume. 


\section{The Analytical Dimensions of Programmes}

Policy decisions have many different aspects. They have a substantive content, and they have formal properties. They are about objectives (or ends) and about instruments (or means). Together, they constitute what is sometimes called a "programme" - the output of the policy formation process and the basis of subsequent routine implementation. To the extent that policy decisions are explicitly formulated and set down in writing, programmes can be empirically analysed independently of the process of their development.

Comparative legal studies have customarily worked with analytical schemes to describe the relevant norms in a given field in detail. In contrast, classical studies of comparative policy analysis have concentrated so much on the substantive content of - for instance - educational or housing policy that no need was felt for a more formalised description of governmental interventions. ${ }^{9}$ But this has changed, and more recently various analytical schemes for the description of programmes have been proposed, some deriving from an interest in the process of legislation, ${ }^{10}$ some stemming from an interest in policy implementation and evaluation. ${ }^{11}$ Some of these schemes are quite elaborate; Jann for instance distinguishes between (1) outcome goals (or policy objectives), (2) various programme elements relating to the desired effects (including choice of policy instrument and definition of the target group), and (3) several programme elements relating to implementation (including definition of implementation agents, funding etc.) - a total of ten analytical dimensions. ${ }^{12}$

The different cognitive interests of legal scholars and political scientists are clearly reflected in the analytical dimensions singled out for the description of programmes. The six dimensions of the scheme for coding legal measures described by Daintith ${ }^{13}$ reflect on the one hand an interest in the question how the use of legal norms for policy purposes comes to influence the character of law: its scope, its temporal validity, and the nature of the relation it creates. On the other hand, the dimensions "substantive content" and "source" express the interest in the different roles that legal norms can play in translating policy objectives into action, and in the legal status of these norms.

9 Quite characteristic in this respect is the book by Arnold J. Heidenheimer, Hugh Heclo, Carolyn Teich Adams, Comparative Public Policy - The Politics of Social Choice in Europe and America, (2nd ed., 1983, New York).

10 Ludwig Göbel, "Probleme der Regelungsform und der Institutionalisierung", in: C. Böhret ed., Gesetzgebungspraxis und Gesetzgebungslehre, (1980, Wiesbaden), at p. 84.

${ }^{11}$ See for instance Peter Knoepfel and Helmut Weidner, "Normbildung und Implementation: Interessenberücksichtigungsmuster" in Programmstrukturen von Luftreinhaltepolitiken, in: R. Mayntz ed., Implementation politischer Programme, (1980, Königstein/Ts.) at pp. $88 \mathrm{f}$.

12 Werner Jann, Kategorien der Policy Forschung, Speyerer Arbeitshefte, (1981, Wiesbaden) at pp. $49 \mathrm{ff}$.

${ }^{13}$ For full details, see the Methodological Note, esp. Appendix C, above, at pp. 47-55. 
In contrast, analytical schemes developed in the context of research policy implementation put great emphasis on a detailed categorisation of operative rules which influence the behaviour of the implementation agents and hence the concrete "output" of the programmes in terms of acts or decisions (see Figure 4). ${ }^{14}$

\section{Figure 4}

Programme elements

I. Core elements explicit objectives, whether these relate to the behaviour of the target group or the intended effect of this behaviour

definition of target group

choice of policy instrument

II. Elements which operationalise the core

designation of implementation agents

administrative procedures

due process rules (complaints etc.)

participation rules

adaptive or self-correction mechanism

internal control procedures

temporal validity

If one is specifically interested in those programme characteristics which presumably influence either the behaviour of implementation agents or the reactions of the target group and interested third parties, the legal properties of concrete measures seem less relevant. In particular I would suggest the hypothesis that the legal status of a given state intervention (as operationalised in the dimension "source") and the role of legal norms within a programme (as operationalised in the dimension "substantive content") are only of minor importance as to its effects, especially for the extent to which it is able to realise policy objectives and to avoid "implementation deficits". To the citizen it probably does not matter much whether what he receives or is asked to do is the content of a law passed by parliament, of a ministerial decree, or of a standard formulated by an independent regulatory agency. In fact, the average citizen is often not familiar with these distinctions and ignores the legal status of norms he is expected to comply with. Provided the content is the same, the legal status per se should not make much of a difference - except perhaps for the chances of successfully opposing or avoiding compliance, since due process norms will differ with the legal status of the

14 Renate Mayntz, Christa Lex, Voraussetzungen und Aspekte administrativer Praktikabilität staatlicher Handlungsprogramme. Wissenschaftliche Ausarbeitung im Auftrag des Bundesministeriums des Innern, (1982, Köln) at pp. $22 \mathrm{f}$. 
substantive norm. It is for such reasons that implementation research has generally paid very little attention to legal programme characteristics.

Where interest shifts from the possible effects to the determinants of policy decisions, the nature of the determinant one is trying to assess again tends to be reflected in the analytical dimensions singled out for coding policy measures or describing programmes. If the legal system is the major factor of interest, other formal and substantive properties of programmes seem relevant than would be the case in a study which attempts for instance to trace the influence of national culture (or political intervention style). In both cases, it is important to identify and focus on those programme characteristics which are likely to be influenced by - and hence reflect - a particular determinant. Thus, in one recent study which sought to test the effect of national culture on social and economic regulation, the intensity (scope, density, and specificity) of the regulation of target group behaviour was used as one of the major formal properties for which programmes were coded. ${ }^{15}$

\section{The Determinants of Policy Design - A Causal Model}

Whereas it is quite evident that it is impossible to infer the effects which a given programme will actually have from its observable characteristics, it seems much less problematic to infer its major determinants from them. In fact, programmes are sometimes analysed because their characteristics are taken to be an indicator of some factor that presumably shaped them. This was true for instance with respect to the determinant "national political and administrative culture", which played the central theoretical role in the comparative study just referred to. To use programme characteristics as an indicator of important factors which played a role in its development appears on first sight plausible enough, considering they have shaped its content and form - much as geological and archeological research interprets sediments and remnants to infer what or who produced them, how, and why. The very use of this parallel, however, alerts us to the theoretical assumptions which must be made in such an interpretation. What, then, are the important determinants of policy decision, and to what extent can they be inferred from observable programme characteristics?

There is no need to argue at length that the legal system, even in the very wide meaning this term is given by Daintith, is only one among many factors which shape the policy decisions incorporated in a given programme. Nor is it very difficult to list the major factors and combine them into a master model, as Figure 5 tries to do.

15 Renate Mayntz, J. Feick, L. Klaes, Ch. Lex, R. Seebach, Regulative Politik und politischadministrative Kultur - Ein Vergleich von fünf Ländern und vier Interventionsprogrammen, Forschungsbericht, (1982, Köln). 
Figure 5: Major Determinants of Policy Output

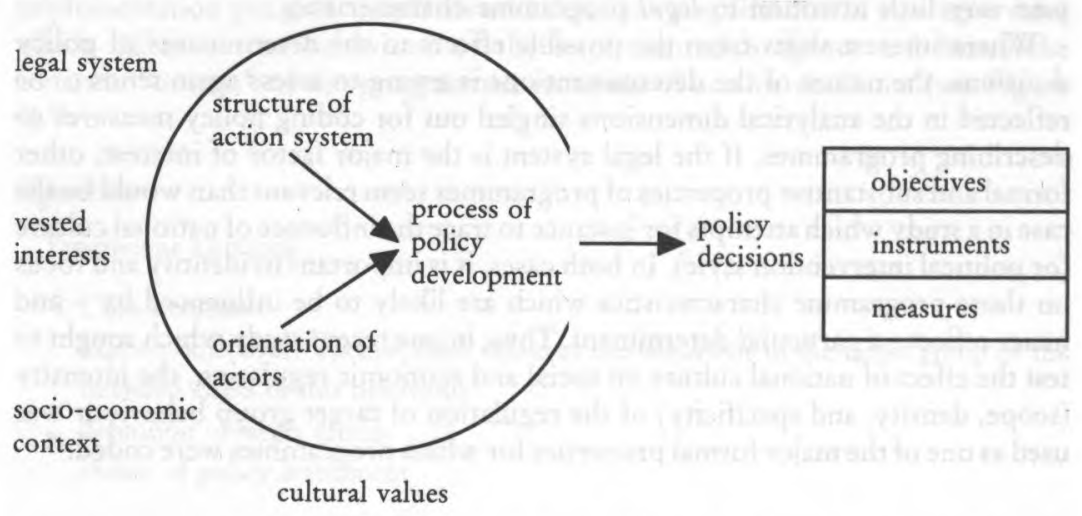

The major components of this model have all been objects of political science, though they were not necessarily seen as linked to policy outcomes. In fact, interest in policy decisions is relatively recent, and, at least in the Federal Republic of Germany, political scientists are currently debating whether or not policy analysis is a basically new approach that is changing the traditional understanding of the discipline. ${ }^{16}$ In particular, scholars of comparative government, the "institutionalists" with their detailed and historically informed descriptions of political structures, have traditionally not linked their analyses of the polity to policy - maybe because (as v. Beyme suggests) the functions of government were an unproblematical datum for them. ${ }^{17}$ The two policy determinants which have been most intensively discussed are the societal power structure (structure of vested interests) and the ideology of governing parties. Very often, the discussion is framed in terms of some alternative, contrasting for instance the relative influence of socio-economic context with that of politics, or of institutions with that of individual attitudes. These debates and the empirical data that have been collected in their support are at times very instructive, but they do not add up to an integrated theory or dynamic explanatory model which would be able to account for observable programme characteristics. Nor is it possible to develop such a model fully in this paper, but it is worthwhile to spell out some of the requirements such a model would have to fulfill.

The plurality of factors which can plausibly be argued to have an influence on the form and content of policy decisions raises the issue of their relative weight. Instead of discussing this by arguing for (or against) the dominant influence of one particular factor, it seems more fruitful to ask how these different factors combine.

16 In November 1984, the German Professional Association of Political Scientists, DVPW, held a symposium on the topic "Zum Verhältnis der Policy-Forschung/Policy Studies zu den 'Kernbereichen' des Faches", where this issue was debated.

17 Klaus v. Beyme, Policy Analysis und traditionelle Politikwissenschaft, paper presented at the symposium mentioned in footnote 16. 
Some of the factors in the model have a direct, some an indirect effect. If one thinks in terms of a concrete policy-making process, the most direct or proximate causes of a given programme design are the decisions taken by specific actors in a specific sequence. These individual decisions are primarily influenced by a number of subjective factors (interests, value orientations, ideological conviction, cognitive models etc.), but the way these individual contributions are aggregated, the amount and kind of influence which individual actors have, are shaped by structural features of the political-administrative system. Many context features become effective by impinging on the action system by determining who participates in the process, and by influencing the choices of policy-makers. Constitutional norms, for instance, general cultural value orientations, or the availability of resources, first become effective when they are taken into consideration in the making of policy decisions in order to avoid such anticipated consequences as the later revision of a statute by the constitutional court, widespread popular resistance to a policy, or the inability to finance a programme. Thus, all background or context factors must be linked to the decisions of individuals in order to shape policy measures. But it is evident that the indirect nature of the influence which such factors have says nothing about their relative weight in determining policy output.

It is also important to recognise that some factors influence policy output by shaping it substantively, while others merely constrain or limit the choice of policy-makers. The preferences of decision-makers have an immediate shaping influence, while constitutional norms and the institutional framework are constraining rather than shaping factors. They narrow the range of feasible choices, but there is no point-by-point correspondence between them and the substantive content of specific policy decisions. While largely constraining, the legal system can also occasionally have a shaping influence, as when for example existing legal norms require certain substantive objectives to be pursued or procedural rules in implementation to be observed, which must therefore be written into a programme.

Most important of all, it should be recognised that not all factors influence the various programme elements to the same extent. At least part of the fruitless debate about the major or minor importance of specific factors results from the neglect of this differential importance of a given factor for different programme elements. In particular, the elements in the programme core, especially the impact goals, the intended distribution of costs and benefits (who receives what or is asked to do what) are likely to be influenced most strongly by other factors than those which affect the design of the operative elements. Nor are these elements. decided on at the same time, or by the same actors, which also means that different criteria may structure the relevant decisions. This conjunction of sequence and orientational differences is important because it may lead to internal contradictions between various programme elements, notably policy goals and their "operationalisation" in specific rules and measures.

If these remarks have served to "dynamise" the static causal model represented in Figure 5 and to clarify somewhat the nature of the relationships between different factors, we can now turn to some of the factors in more detail. 
Socio-economic variables exert an indirect influence on policy outputs, but are generally considered to be very influential. Two schools of thought in particular have concentrated on these determinants: neo-marxists, who have focused on the macro-social power structure (or structure of vested interests), and welfare state theorists, who have focused instead on the stage of socio-economic development which a country has reached. Neo-marxists tend to assign a merely instrumental role to political institutions and to deny political actors the power of effecting real choices. For them, policy content is shaped by the dominant class interests which are reflected in particular in the substantive policy goals and in the cost/benefit implications of the measures for the major socio-economic groups. ${ }^{18}$ Welfare state theorists focus on the substantive content of social policy decisions, especially the introduction of social security measures. Their view is less deterministic, in that they recognise that in addition to socio-economic variables such as the degree of industrialisation, political variables like democratisation or the existence and strength of labour parties also play a role, and the relative weight of these two kinds of variables is one of their major research interests. ${ }^{19}$ In both analytical traditions, formal programme properties are generally not considered, and it is indeed difficult to construe relationship which could plausibly link them to socioeconomic background variables.

As we move from the socio-economic context to the political action system which produces the policy decisions, three sets of factors which influence their form and content can be distinguished: the structure of the political action system, the preferences, orientations, and attitudes of the individual political actors, and the process of policy development, in which various political actors within a given institutional framework participate over time in a collective decision process.

The structure of the political action system is a favourite research object of political scientists, but scholars in the field of comparative government have in general not tried to identify the policy consequences of specific institutional arrangements. ${ }^{20}$ The neo-corporatist school of thought is a notable exception, even though the emphasis is here less on the form and content of policy decisions than on their effects. ${ }^{21}$ Still, it is highly plausible that structural features of the political action system such as a country's party system, the role which the head of government plays, or the relative weight of parliament and ministerial bureaucracy in drafting legislation, will, if indirectly, affect policy decisions. Overall structural properties such as the relative openness of a political action system to

18 Joachim Hirsch, Staatsapparat und Reproduktion des Kapitals, (1974, Frankfurt) is a good illustration of this approach as applied to German science and technology policy.

19 See for instance H. L. Wilensky, The Welfare State and Equality. Structural and Ideological Routes of Public Expenditures, (1975, Berkeley); also Peter Flora, Arnold J. Heidenheimer (eds.), The Development of Welfare States in Europe and America, (1981, New Jersey), esp. chapts. 2, 4 and 5.

20 A typical example is R. Rose, E. Suleiman (eds.) Presidents and Prime Ministers, (1980, Washington D.C.).

${ }^{21}$ G. Lehmbruch, Ph. C. Schmitter, Patterns of Corporatist Policy-Making, (1982, Beverly Hills/London). 
the demands of organised and unorganised interests, or the relative concentration or dispersion of decision-making power, can influence such general characteristics of policy outputs as their responsiveness, timeliness, coherence, and reactive or proactive nature. Of course, this kind of relationship can only be identified if the programme output of several countries is compared, and if a larger number of programmes is considered, which may be one reason why there are no systematic empirical tests of such hypotheses.

The structural features of the political action system have also an - indirect influence on the content of specific policy decisions, because they determine the relative power of different political actors and their specific functions in the collective decision process. However, institutions only provide the framework within which action takes place, and in order to predict a specific policy output, it would be necessary to know not only the involvement and relative power of particular actors, but also their substantive preferences, which are the factors that find the most direct expression in policy decisions. These preferences, incidentally, do not only relate to policy goals (or the intended distribution of costs and benefits), but also to such programme characteristics as the type of instrument or the choice of implementation agents. That the ideological orientation of policymakers influences their decisions has always been assumed, though expectations that their social origin might find a direct expression in the public policy adopted have been largely disappointed. ${ }^{22}$ The simple truth that only the combination of the - facilitating and restricting - structure of the action system with the specific orientations of given actors produces whatever effect politics have on policy is neglected by pure "institutionalists" and pure "behaviourists" alike.

An attitudinal factor which has recently attracted a growing amount of attention is summarily designated by the term national (political, administrative) culture. These attitudinal factors presumably characterise the policy-makers in a given country by virtue of their belonging to a specific national culture. In the United States for instance this would be a pronounced individualism and a general preference for reliance on individual self-help and free market forces rather than the state. It seems obvious that different intervention philosophies, different "ways of doing things", can grow out of different cultural value orientations, but they can also be influenced by the social background, training, and the career experience of policy-makers, factors which produce a specific sub-culture. It may even be meaningful to break down the cultural factor further by distinguishing between the sub-cultures of bureaucrats and of politicians. Cultural factors should not so much influence the choice of policy objectives as the choice among different types of instruments and among potential implementation agents, as well as a number of formal characteristics such as the generality or specificity of legal norms or the scope for discretionary action left to implementation agents. ${ }^{23}$ Again, however, national intervention philosophies or "ways of doing things" do not

22 See for instance the various contributions to the volume edited by Moshe M. Czudnowski, Does Who Governs Matter? (1982, Illinois).

23 This is suggested by a study of Werner Jann, Staatliche Programme und 'Verwaltungskultur', (1983, Opladen). 
only derive from attitudinal factors, but are likewise shaped by structural constraints, such as the cooperative or antagonistic relationship between central and local governments and the existence or non-existence of administrative courts.

When process features were mentioned as a final major set of factors, reference was made not only to "politics", i.e. the power struggle between opposing parties, organised interests etc., but also to properties of the collective decision process in which policy is being developed. Process features are dealt with in a number of studies and theories which basically try to show that the reality of policy-making differs from the normative model of rational decision, and just how it does so. Some, but not all of these studies have explicitly pointed to the impact which the nature of the collective decision process has on substantive policy output. Already in 1959, Lindblom thus saw that the incrementalist character of policy was related to the pervasive bargaining and compromising which characterise the political decision process in a highly pluralistic society. ${ }^{24}$ On the basis of an empirical study, Mayntz and Scharpf have later argued that the short-term, small-scale, and reactive (rather than long-term, comprehensive, and proactive) nature of the programmes generated in the German federal bureaucracy is the outcome of what was described as a dialogue process linking together in a collective decision process policy-makers located in different parts of the system. ${ }^{25}$ Another approach called "bureaucratic politics" has emphasised how the power struggle between organisations, domain interests, and procedural routines shapes the strategic choices of decision-makers. It is evident that this must have an effect on the decisions produced; in fact, Allison, who first developed this approach, started with the attempt to explain the specific set of decisions taken by the US government in the Cuban missile crisis. ${ }^{26}$ The assumed relationship of process to specific output features is weaker in March and Olson's "garbage" can model of decision processes, or Nedelmann's model of conflict transformation in processes of policy development. ${ }^{27} \mathrm{~A}$ basic thesis of these models is that in the course of the collective decision process, the initial problem (or conflict) becomes dissociated from the decision output. The decisions which are finally produced do not only reflect theoften non-issue-related - interests and strategies of a fixed set of actors, but the sequence in which different participants have entered and maybe left the process again. It may be, however, that the most important influence of the process characteristics considered in these models, i.e. how closely policy development

${ }^{24}$ Charles Lindblom, "The Science of 'Muddling Through", in: PAR 2/1959; later extended in the book: The Intelligence of Democracy. Decision-Making Through Mutual Adjustment, (1965, New York).

25 Renate Mayntz, Fritz W. Scharpf, Policy-Making in the German Federal Bureaucracy, (1975, Amsterdam/New York).

${ }^{26}$ Graham T. Allison, Essence of Decision. Explaining the Cuban Missile Crisis, (1971, Boston); Graham T. Allison, Morton H. Halperin, "Bureaucratic Politics. A Paradigm and Some Policy Implications", in: Raymond Tanter, Richard H. Ullmann eds., Theory and Policy in International Relations, (1974, Princeton) at pp. 40-79.

27 J.G.March, J.P.Olsen, Ambiguity and Choice in Organisations, (1976, Bergen); B. Nedelmann, Rentenpolitik in Schweden, (1982, Frankfurt/New York). 
approximates to a rational decision process, is not on the form and content of programmes, but on a property that cannot be derived from programme characteristics themselves: their potential effectiveness or problem-solving capacity.

\section{The Theoretical Potential of Comparative Policy Research}

The plurality of factors which shape policy decisions and the complexity of their interactions present an obvious problem when it comes to making inferences from programme characteristics which can be studied by documentary analysis. Since the effects of various factors may combine, overlap, reinforce, or cancel each other out, it is impossible to derive the major factors which shaped a programme from its observable features with anything approaching certainty. In fact, one and the same substantive decision can easily result from a variety of different power constellations, bargaining processes, and sets of preferences. By adopting a comparative design in which some factors are varied while others are held constant, this confusing complexity can be somewhat reduced. In order to vary socio-economic context, the legal system, the institutional framework, and an attitudinal factor such as national culture, an international comparison is necessary. The major problem in such a design is to make a country selection which does not vary all of these factors at the same time (and in different directions), though this is what normally happens. It is also possible to focus the comparative design by selectively coding observable measures for those features on which the chosen explanatory variable should exert a particularly strong influence. In this way, the problem of causal attribution can be somewhat mitigated, but it can hardly be solved. For purposes of illustration let me refer to some results of the five-country-comparison referred to before, a study which I initiated and where we attempted to identify the influence of national culture or intervention styles, on regulatory programmes - in particular on the intensity (scope, density, and precision or specificity of rules) of regulation. ${ }^{28}$

As in the case of Daintith and Teubner's research, our data consisted largely of written documents containing the various measures, which we analysed for a number of formal characteristics including intensity of regulation, but also for their manifest objectives, their source and legal status, and details of the instrument (the general type being a constant). If there really is anything like a "national intervention style", this should become visible as a kind of common denominator of the politicies adopted in a given country. We chose therefore three different regulatory problems - the containment of epidemic diseases, drug regulation, and commercial freight traffic regulation - and analysed these for each of the five countries covered. As in the study which is the subject of this volume, we attempted to select policy problems which by and large could be considered as constants, i.e. that did not vary from country to country. In the attempt to order the rich detail of our findings we adopted rough scales (high-medium-low) for our major formal dimensions and aggregated the results by country and by policy

28 Supra, note 15. 
field. Figure 6 gives an example. As can be seen, the results are anything but conclusive. There are differences between countries in what we have called intensity of regulation, and by and large they confirm what national stereotypes would have led one to expect. However, the differences are not very pronounced, and there is considerable variance within countries from policy field to policy field, so that in the aggregate, the intensity of regulation varies as much between policy fields as it does between countries.

Considering this result, the question arises of what is it that we have varied by selecting these different policy fields. To begin with, each policy field has a different structure: a different kind of target group, different vested interests, a different problem-solving technology. Also, different sets of policy-makers may be involved, and different sets of implementation agents may be available. In the regulation of drug production and commercial freight traffic, for example, powerful and organised interests are involved who may have resisted very strict measures, while in the containment of epidemic diseases, there may have been a more widespread consensus as to the necessity of strict measures, and this may be reflected in the different scores in Figure 6. Thus, any attempt to explain the residual variance not accounted for by the major determinant singled out for analysis inevitably draws attention to additional factors which, however, have not been systematically controlled. It is likely that the comparative analysis of manpower and of energy policy in different European countries will lead to similarly inconclusive results, both with respect to explaining the links between objectives, instruments, and legal measures which go beyond mere logical implications, and to the shaping influence of the legal system.

Figure 6: Intensity of Regulation of Target Group Behaviour ( 3 = low, $9=$ high for scope, density, and specificity)

\begin{tabular}{lcccccc}
\hline & Belgium & Germany & France & $\begin{array}{c}\text { Great } \\
\text { Britain }\end{array}$ & Italy & $\begin{array}{c}\text { Average } \\
\text { score }\end{array}$ \\
\hline $\begin{array}{l}\text { Containment of } \\
\text { epidemic diseases }\end{array}$ & 9 & 9 & 9 & 7.5 & 9 & 8.7 \\
$\begin{array}{l}\text { Drug regulation } \\
\begin{array}{l}\text { Commercial freight } \\
\text { traffic }\end{array}\end{array}$ & 6 & 3 & 6 & 8.25 & 8.25 & 6.3 \\
\begin{tabular}{l} 
Average score \\
\hline
\end{tabular} & 6.3 & 7 & 7.7 & 6.6 & 8.8 & \\
\hline
\end{tabular}

The discussion in the previous section alerts us to yet another methological limit which confronts comparative policy studies that are based merely on documentary evidence. Some of the most salient effects of the main policy determinants cannot be inferred from observable programme characteristics alone. This holds for instance for the timeliness, the responsiveness, the reactive or proactive nature and the cost/benefit implications of a policy, which presuppose extensive contextual information (e.g. about the nature of a problem, the interests actually involved, etc.) before they can be attributed to a given programme. 
To point to the inherent methodological limits of attempts to infer what shaped a policy from its directly observable characteristics should not be regarded as an unfair criticism of the approach chosen in this research. For one thing, documentary analysis can be very helpful in the process of legalisation (or de-legalisation) in a longitudinal perspective. It is well to remember also that Daintith himself is not primarily interested in the determinants of the characteristics for which he is coding the policies selected for analysis. The attempt to ask what these factors are and how far they might be inferred from observable programme characteristics, though stimulated by the work of Teubner and Daintith, goes at least partly beyond the scope of their present research - without, I hope, therefore seeming irrelevant. 